\title{
2-dimensional investigation of in-cylinder flow and turbulence at suction stroke in internal combustion 4-stroke engines
}

\author{
Ibrahim CAN ${ }^{1, *}$ (i), ilyas GÜLDES ${ }^{2}$ \\ ${ }^{1}$ Sivas Cumuriyet Uni., Faculty of Technology, Department of Automotive Engineering, Sivas / TURKEY \\ ${ }^{2}$ MTAL, Motor Vehicle Technology Area, Sivas / TURKEY
}

\begin{abstract}
Studies and experiments conducted for the performance enhancement of internal combustion engines are of great importance. Today, challenges encountered in securing energy resources, the incremental costs and environmental factors constantly remind us that we should not ignore fuel economy in motor vehicles. Studies conducted in this framework focus on lower fuel consumption and less exhaust emissions while improving performance. Undoubtedly, combustion chamber designs and charge systems have a great effect on exhaust emissions and performance. For this reason, a suction stroke was modeled in two dimensions using the fluent software to better understand the charge systems in internal combustion engines. The design was based on 1600 cc Fiat engine measurements and engine geometry was defined. CFD (Computational Fluid Dynamics) software was used to investigate the valve opening and cylinder and combustion chamber air motion at 900, 3000, 5000 rev-1 RPM and the results were discussed in detail. CFD results will assist engine designers in understanding the effects of suction system and its components on various parameters.
\end{abstract}

\section{Article info}

History:

Received: 21.09 .2020

Accepted: 25.12 .2020

Keywords:

Combustion Chamber,

Intake Air,

Turbulence,

CFD.

\section{Introduction}

Internal combustion engines are widely used today, especially in the automotive industry but also in many sectors that require power and performance. However, what is expected of internal combustion engines is not only power and performance. Besides performance, emission values are also important because they are stricter with international agreements such as the Kyoto Protocol and increased environmental awareness. Numerous studies have been and are being conducted to improve the problems pointed out by engine manufacturers and researchers. One of the focal points of these studies is the investigation of incylinder charge and its motions.

With advancements in computer technology, modeling and simulation techniques reduce design and production costs. Performance and design optimization of internal combustion engines is primarily carried out using computerized simulation models, and necessary calculations and adjustments are easily compared using the generated models. Studies conducted using these models focus on the analysis of in-cylinder air motions, the design of combustion chambers, the determination of valve positions and sizes, effects of piston head shape on in-cylinder air motions and combustion, and the determination of spark plug and injector positions. The literature contains many studies on engine modelling and experimental investigation of findings.

The amount of filling and flow movements inside the cylinder are shaped in the suction event. The 4-stroke engines are also the narrowest section for the suction valve flow, so the gas flow rate in this section is highest during suction.

The gas flows and disperses into the cylinder in the form of a conical spray. The axial and radial velocity in this cross-section is about 10 times greater than the piston speed [1]. In particular, the flow with a chokelike character interacts with the cylinder walls as the piston moves, creating large rotational flow patterns in the cylinder. These flows interact significantly with the cylinder head geometry, valve and intake manifold and its structure changes during both compression and suction and are distorted by transforming into threedimensional turbulence motion [2].

Akar et al. [3] studied flow characteristics in a combustion chamber using FLUENT as a computational fluid dynamics code. They determined 
that valve opening and cylinder length have an effect on flow characteristics in a single-valve engine with a flat combustion chamber. This result was confirmed by comparing it with those of the previous experimental studies [4].

M. C. Drake et al. injected fuel directly into the cylinder in two stages by making modifications to a four-stroke, single-cylinder and four-valve spark ignition engine. They adjusted the mixing balance by separating the air inlets of the suction valves. They used CFD method to model fuel injection, combustion and air fuel mixture to determine optimum values of fuel consumption and exhaust emission. They numerically compared the CFD model results with the actual conditions of the engine. They stated in the conclusion section of the study that the results of the model and the experiment were compatible $[5,2]$.

$\mathrm{Wu}$ and Perng used Large Eddy Simulation model to investigate heat transfer and turbulence during compression and exhaust stroke in automobile engines. They used the standard k-s model for numerical studies and the Cholesky gradient method for solving singular equations. They calculated local heat flux and eddy velocity at different crank angles for two different types of piston a plain head piston and a dish piston. They compared the results with those of experimental studies $[4,6]$.

Altın and Bilgin analyzed the effect of twin spark plugs on engine performance at different rotations in a twodimensional cycle in a spark-ignition engine with a disc-type combustion chamber. They investigated mean pressure, efficiency, specific fuel consumption and power for different spark plug positions using single and double spark plugs in combustion chambers. The spark plugs were positioned axially symmetrically with respect to the center of the cylinder head at 5 different points with a difference of 0.25 . Data were compared with those of experimental results in the literature. They reported that the position of the spark plugs with respect to the center had a direct effect on combustion time, which was extended. Two negative consequences were identified. One of them is straying from the Otto cycle, that is, the ideal cycle. The other one is the increase in heat loss to the cylinder walls as time progresses. In both cases the thermal efficiency drops $[4,7]$.

Coşkun et al conducted a combustion analysis of an HCCI engine using computational fluid dynamics. In the study, piston movement 720 time intervals were defined For the $360^{\circ}$ crankshaft angle and 30 iterations were determined for each time interval and the combustion regime of the existing air-fuel mixture was examined when the piston was in the bottom dead center [8].

In internal combustion engines, the volume between the piston and the cylinder head constitutes the combustion chamber when the piston is at top dead center. It is desirable to obtain high pressure by constant volume combustion in Otto cycle engines. The realization of the combustion process in the combustion chamber volume within the shortest time directly affects the post combustion pressure.

Ideal burning: It depends on the air-fuel mixture ratio, the homogeneity of the mixture and the position of the spark plug with the strength of the spark. The homogeneity of the air fuel mixture depends on the motions of vortices varying according to the position of the valves, shape of the piston head and of the combustion chamber. The turbulences that occur improve the combustion, but irregular turbulences cause the breakdown of the combustion.

Vortex and turbulence generated in cylinders play an important role in determining combustion characteristics. Although the positive effects of the turbulence effect on combustion in internal combustion engines have been known theoretically for a long time, it is quite difficult in practice to design the combustion chamber geometry and suction ports to obtain the turbulence required for good combustion [2].

Several combustion chambers have been used to achieve ideal combustion, better exhaust emissions, high power output and high performance in internal combustion engines. Combustion chambers vary according to parameters such as vehicle type and engine characteristics, and the desired power and lower emission values are also important in determining this engine's characteristics. Combustion chambers can now be customized for production companies in the automotive industry. They also have distinctive models thanks to studies on this subject. Shape changes in combustion chambers can be diverse based on piston shape, number of valves, valve shapes, etc. Some of the most common combustion chambers are $[4,9]$ :

- Hemispherical combustion chamber,

- Pent-roof combustion chamber,

- Wedge combustion chamber,

- Bathtub combustion chamber

Fuel used in internal combustion engines varies depending on fuel type and theoretical cycle of the engine. As can be seen from Figure 1, internal combustion engines have two different type charging 


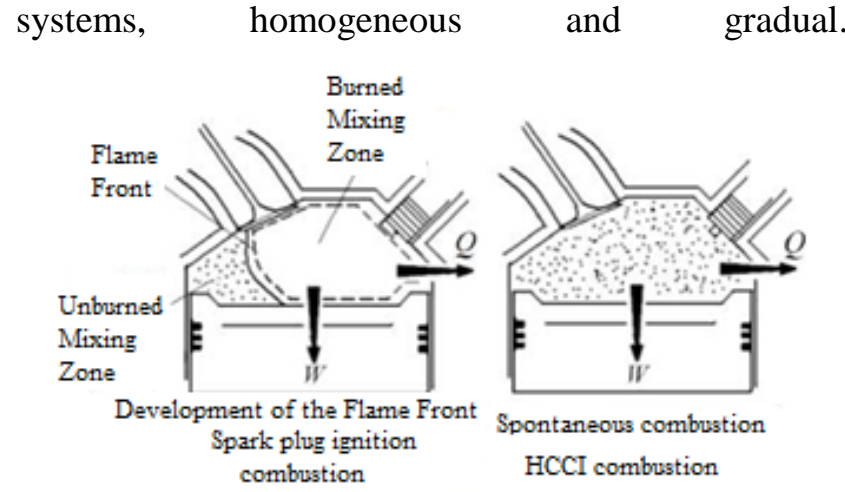

Figure 1. Spark ignition combustion and HCCI combustion [10 - 15]

The vast majority of the engines produced to date have been homogeneous-charge engines. The air and fuel must be stoichiometric to prepare the mixture in homogeneous-charge engines. Therefore, the most suitable air/ fuel mixture preparation system for the homogeneous-charge system is the multipoint injection (MPI) system in which injection must take place behind the suction valve and the fuel injected must consist of very fine particles for mixture sensitivity. Injection time depends on engine RPM. At high speeds, the suction stroke is shortened and therefore, injection which starts when the suction valve is closed, continues as long as the valve is open. Thus, fuel evaporation occurs in the cylinder, and the air fuel mixture becomes more homogeneous than when fuel evaporates in the manifold [2].

Newer and more stringent exhaust emission standards around the world and decreasing fuel reserves call for some modifications to internal combustion engines. Pre-mixed homogeneous charge compression ignition engines (HCCI) with common characteristics of both spark ignition engines and compression ignition engines are one of the main areas studied in the literature. HCCI engines are promising as a combustion mode with advantages that can meet high thermal emission and exhaust emission standards. HCCI engines can operate on poorer mixtures and provide simultaneous reduction of NOx and carbon emissions, resulting especially from diesel engines [11-12]. Combustion process in HCCI combustion mode results from simultaneous combustion of homogeneous-charge premix in the combustion chamber [13].

Even though optimum settings are achieved in conventional homogeneous-charge engines, the fuel consumption of gasoline engines is high. This is mainly due to the fact that the compression ratio is low owing to certain limits and lean mixtures cannot be used as in diesel engines. One of the most important solutions to this problem is the stratified charge principle, which allows gasoline engines to operate on lean mixtures [14]. The stratified charge principle was first applied by Ricardo in 1918. Engines operating on this principle are referred to as "stratified charge engines" [15]. The reason for the increase in efficiency is the rich mixture around the ignition plug and lean air fuel mixture in the other parts of the combustion chamber provided by the stratified charge system. The total excess air coefficient (EAC) of the mixture in the combustion chamber is in the lean region. It has been shown that in-cylinder temperature decreases, and specific heat and transfer also decrease by extension and chemical degradation does not occur as a result of the combustion of the lean mixture. It has also been stated that pumping losses will be reduced as the required throttle opening for the load adjustment increases. Thus, the load can be adjusted by changing the mixture ratio without throttle opening in stratified charge engines as in diesel engines [2]. Figure 2 shows the twin swirl combustion chamber mechanism as an example of the stratified charge.

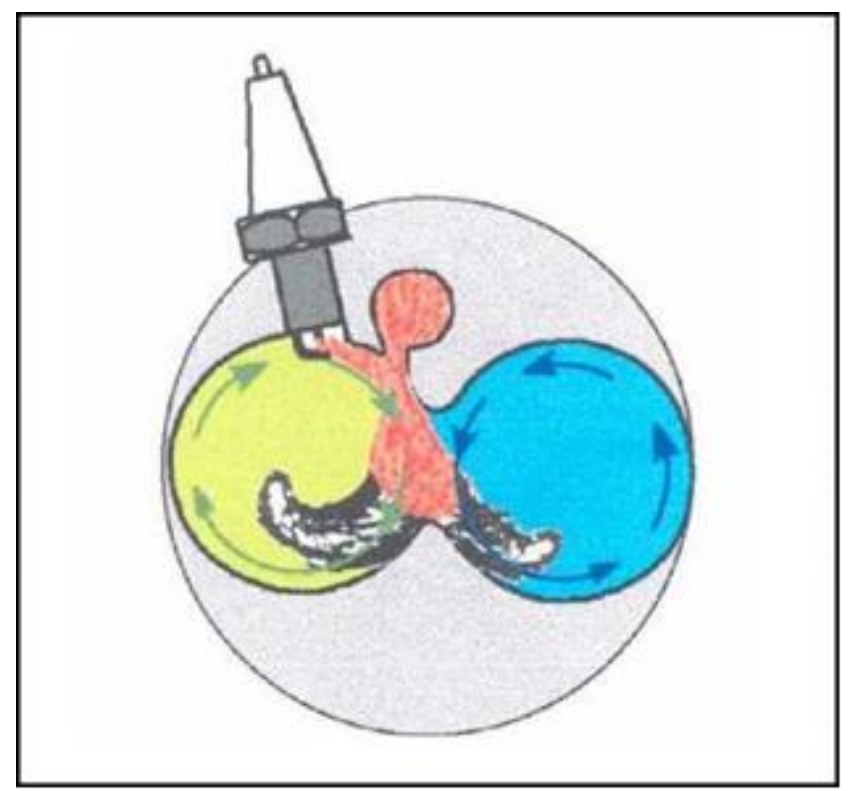

Figure 2. Two-stage combustion mechanism scheme in twin swirl combustion chamber [16]

Mitsubishi introduced its gasoline direct injection (GDI) engines in 1996 [16]. The pre-combustion chamber was removed from this engine, which was not adapted to be fed with a rich air fuel mixture, and the combustion chamber in the piston was designed in such a way that fuel droplets injected into the cylinder at high pressure are directed towards the ignition plug in all load regimes, which makes the rich air fuel mixture possible. Fuel, when injected into the cylinder, changes with the aid of the electronically controlled injector depending on the load regime. Fuel is injected at suction stroke in order to generate a homogeneous 
mixture in the cylinder at full loads while it is injected at compression stroke in order to generate a stratified charge in the cylinder at partial loads. Depending on the load, EAC X ranges from 1.0 to 3.5, thus making the engine highly efficient and economical [16].

\section{Material and Method}

The aim of the study is to examine the in-cylinder motion of air fuel mixture injected into the combustion chamber during the suction stroke in a gasoline engine. To do this, a two-dimensional geometric shape consisting of combustion chamber, valve and piston head was drawn using 1.6 engine scales of Fiat Tempra in accordance with catalog data in Table 1.

Table 1. Trademark catalog data of the test engine

\begin{tabular}{ll}
\hline \multicolumn{1}{c}{ Trademark } & \multicolumn{1}{c}{ Fiat } \\
\hline Number of cylinders & 4 \\
Diameter X Course & 86,4 X 67,4 mm \\
Cylinder volume & $1581 \mathrm{~cm}^{3}$ \\
Maximum RPM & $5800 \mathrm{RPM}$ \\
Maximum power & $62 \mathrm{~kW}$ \\
Compression ratio & 9,2 \\
Combustion chamber volume & $33,7 \mathrm{~cm}^{3}$ \\
Valve Diameter & $39,5 \mathrm{~mm}^{\circ}$ \\
Valve Seating Angle & $45 \AA$ \\
\hline
\end{tabular}

Mean piston speeds were selected as 900 RPM, 3000 RPM and 5000 RPM, which are the common operating speeds, and based on these values, the air velocity at the valve opening was calculated to measure the intake valve opening of the piston for each $30^{\circ} \mathrm{CA}$ after TDC (Top Dead Center) and suction at the start of its stroke. In-cylinder turbulence for each degree was analyzed and photographed using the ANSYS. PRODUCTS. V15.0.7.WIN64-MAGNiTUDE Fluent software package.

The aim of the study is to examine the movements of the air fuel mixture in the cylinder at the time of suction in a gasoline engine. For this purpose, the Fiat Tempra vehicle was drawn in two dimensions in accordance with the geometric figures catalog values consisting of combustion chamber, valve and piston crown by using the 1.6 engine dimensions. For analysis of 2D geometry obtained, mesh network structure was created by using tetrahedral network structure in ANSYS / FLUENT analysis program. Necessary improvements have been made, especially on narrow and thin edges. Before starting the analysis, the network structure conformity check was checked in the skew section and the problematic parts were corrected. After confirming the suitability of the network structure, FLUENT section was started to define the analysis parameters. In this section, the standard $\mathrm{k}-\mathcal{E}$ turbulence model has been chosen to examine incylinder vortexes and their quantity, which is the purpose of the study. Boundary conditions are determined by naming the inlet, valve, wall and piston. $\mathrm{He}$ average piston speeds of the engine for $900 \mathrm{rpm}$, $3000 \mathrm{rpm}$ and $5000 \mathrm{rpm}$ are calculated and based on these values, the air velocity at the valve opening is calculated, the intake valve at the beginning of the suction and for every $30^{\circ} \mathrm{CA}$ after TDC the gap was measured and the turbulence events occurring in the cylinder for each determined degree were analyzed and post-processing was photographed.

\section{Results and Discussion}

Piston positions of the engine at the beginning of the suction stroke at speeds of 900 RPM, 3000 RPM and 5000 RPM were selected at $-20^{\circ}$ crankshaft angle before piston TDC, and at $30^{\circ}, 60^{\circ}, 90^{\circ}, 120^{\circ}, 150^{\circ}$ and $200^{\circ}$ crankshaft angle after piston TDC. Flow rates were examined with reference to the piston speeds at those angles.

The air fuel mixture sucked into the cylinder by the difference of pressure during the suction stroke produces turbulence depending on the valve position, shape of the combustion chamber and piston head shape. Depending on the valve opening, there are also some small vortices around the two main turbulences. The air fuel mixture becomes richer where vortices are dominant while it becomes leaner at sharp edges and corners. To overcome this problem, those sharp edges and corners in the cylinder must be rounded. 


\subsection{Air motions at 900 RPM suction stroke}

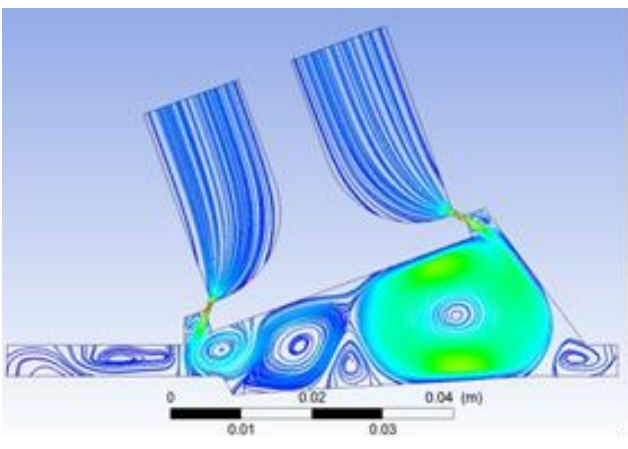

Figure 3 Beginning of suction stroke $-20^{\circ} \mathrm{CA}$

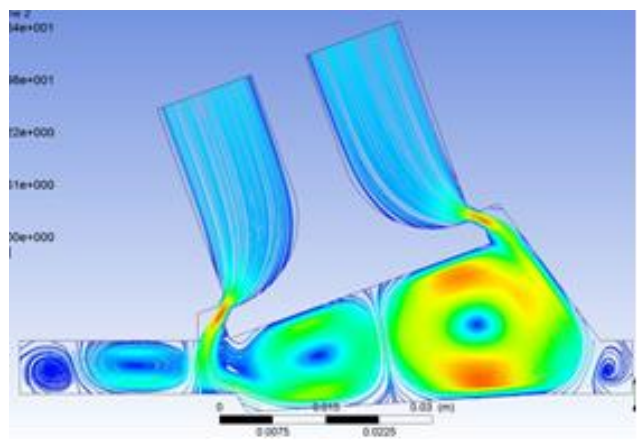

Figure 4 Suction stroke $30^{\circ} \mathrm{CA}$

The piston is $2.55 \mathrm{~mm}$ below TDC when the engine is at the operating condition of $-20^{\circ} \mathrm{CA}$ at $900 \mathrm{RPM}$, and the valve opening is $0.65 \mathrm{~mm}$ when it operates at a speed of $2.022 \mathrm{~m} / \mathrm{s}$ at the beginning of the suction stroke. Under these circumstances, the air fuel mixture introduced into the cylinder reaches its maximum speed $(9.67 \mathrm{~m} / \mathrm{s})$ and generates three main vortices. Due to the sharp edges of the cylinder, small and weak vortices are formed. Figure 3-4 shows the two main vortices formed when the piston moves to $30^{\circ}$ past TDC.

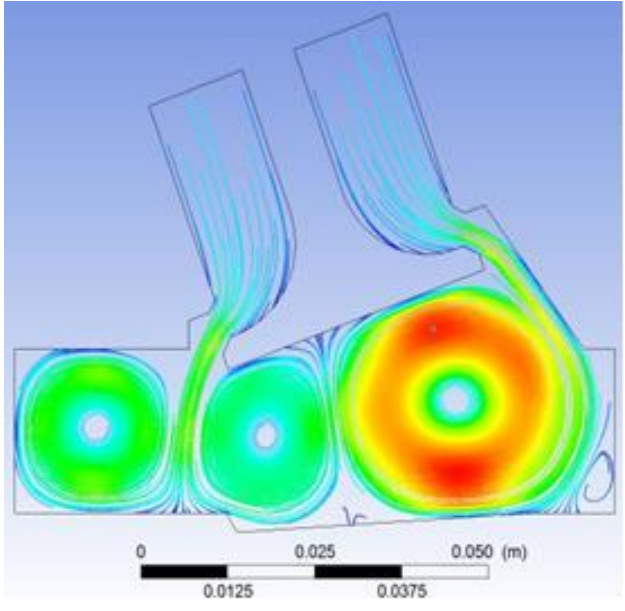

Figure 5 Suction stroke $60^{\circ} \mathrm{CA}$

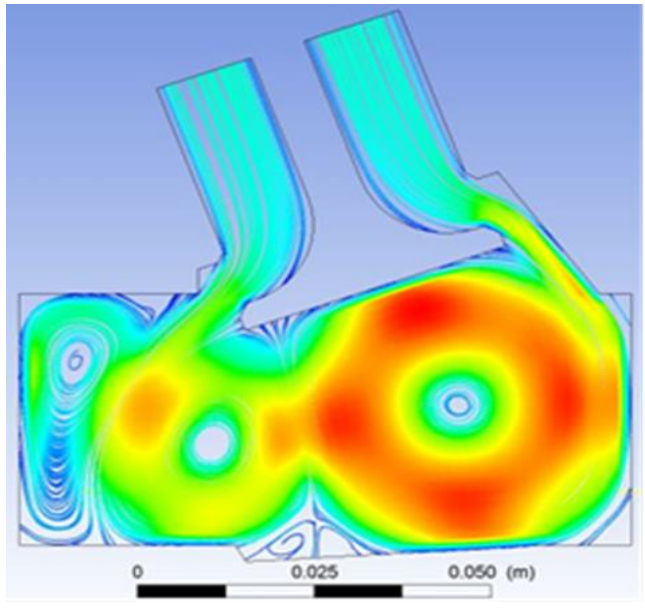

Figure 6 Suction stroke $90^{\circ} \mathrm{CA}$

Figure 5 shows that due to the geometrical shape of the combustion chamber and piston head, small vortices on the left side of the cylinder merged to form a third distinct vortex at $60^{\circ} \mathrm{CA}$. The two main vortices grew to a large size, which led to the concentration of the air fuel mixture in this region, and the third vortex changed shape along in the Figure 6 cylinder at $90^{\circ} \mathrm{CA}$.

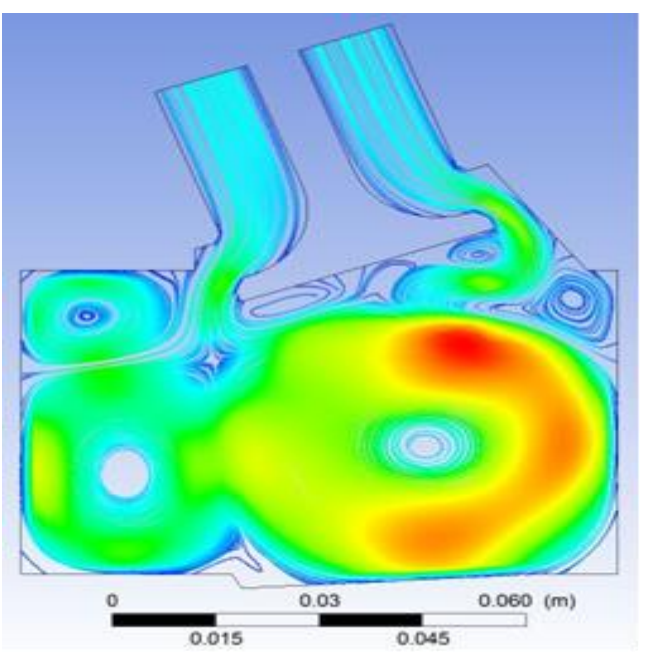

Figure 7 Suction stroke $120^{\circ} \mathrm{CA}$

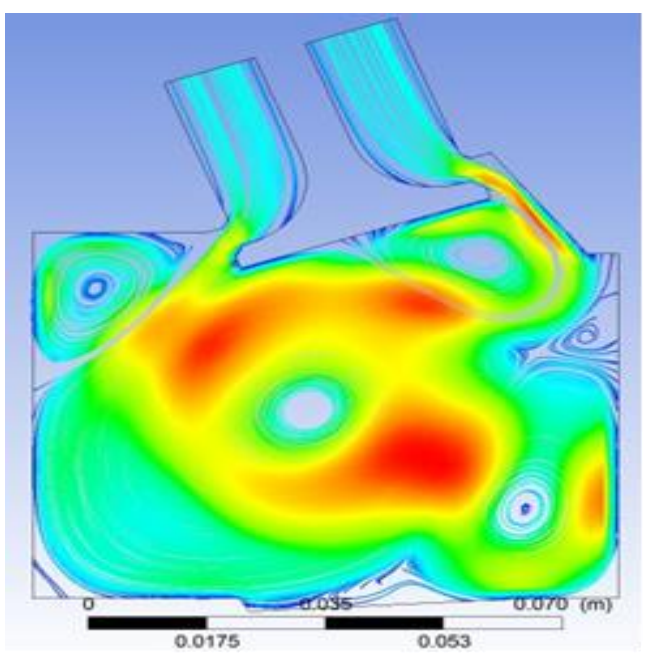

Figure 8 Suction stroke $150^{\circ} \mathrm{CA}$ 
Figure 7-8 demonstrates that the two main vortices grew to a large size and some small vortices were formed due to the geometrical shape of the combustion chamber. At $150^{\circ} \mathrm{CA}$, the air fuel mixture was concentrated in the middle of the cylinder.

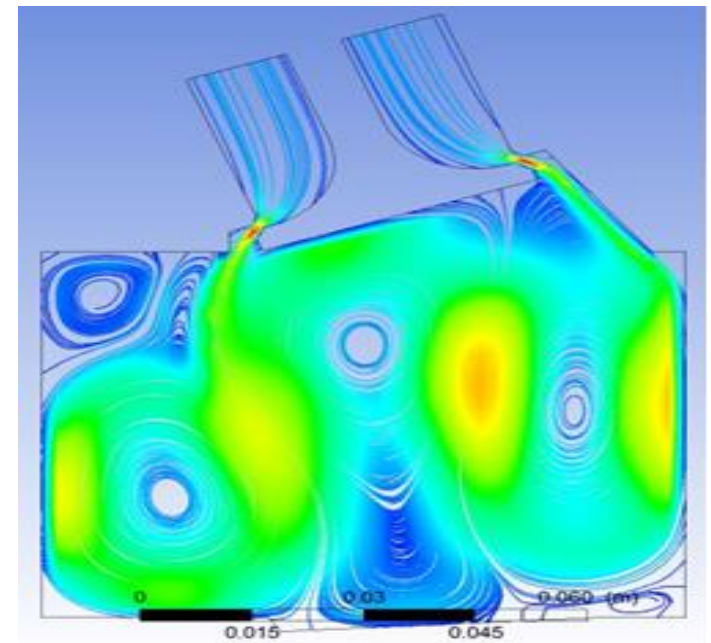

Figure 9 Suction stroke $180^{\circ} \mathrm{CA}$

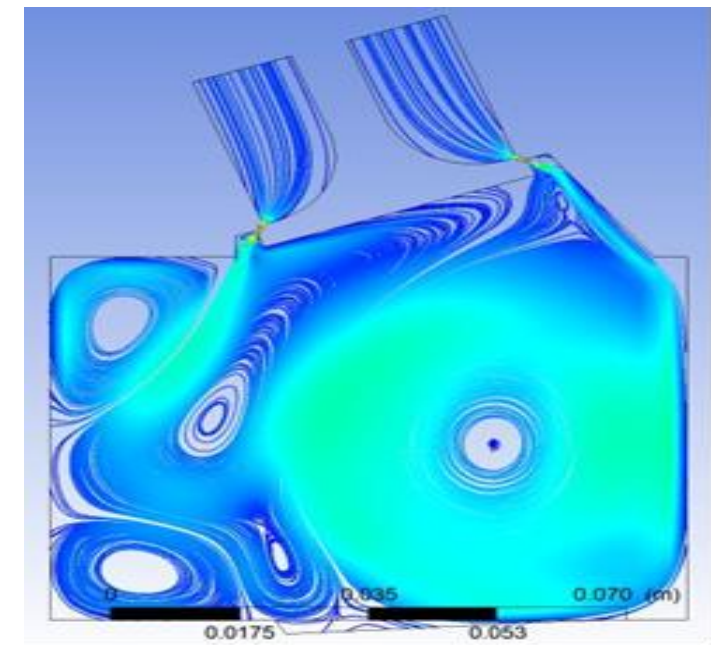

Figure 10 End of suction stroke $200^{\circ} \mathrm{CA}$

Figure 9-10 demonstrates that regional concentrations in the air fuel mixture increased, losing its previous density at $180^{\circ} \mathrm{CA}$. The in-cylinder flow decreased with the suction valve $(0.65 \mathrm{~mm})$ closing as the suction stroke was coming to an end at $200^{\circ} \mathrm{CA}$. There was a main vortex near the spark plug and small vortices in the other parts. The composition of the big vortex was richer than those of the others.

\subsection{Air motions at 3000 RPM suction stroke}

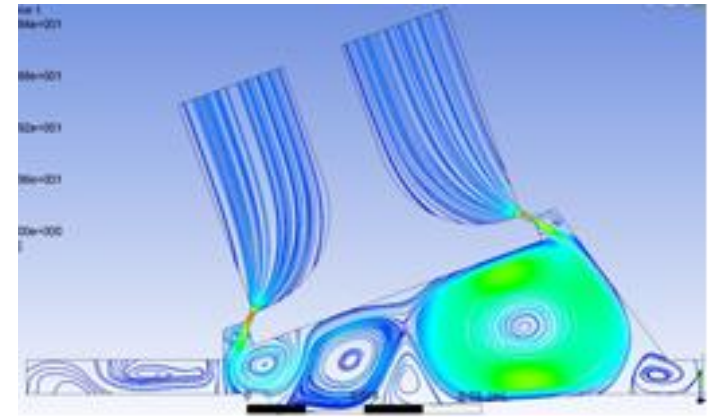

Figure 11. Beginning of suction stroke $-20^{\circ} \mathrm{CA}$

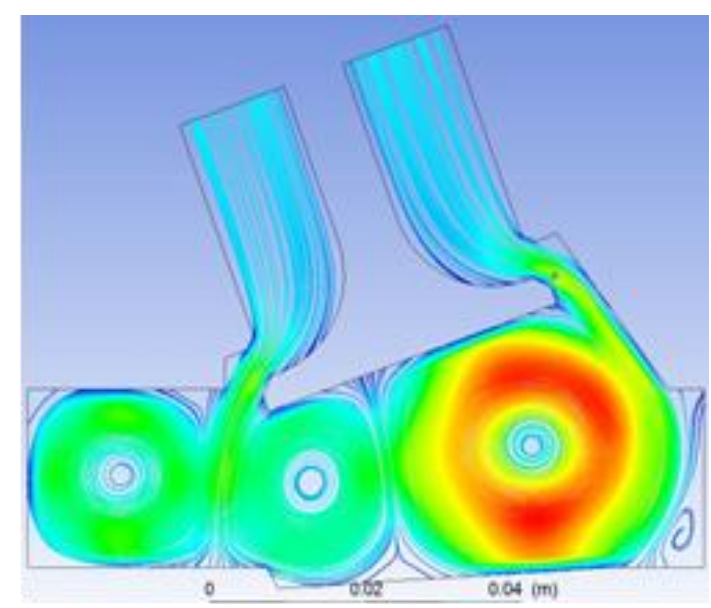

Figure 13 Suction stroke $60^{\circ} \mathrm{CA}$

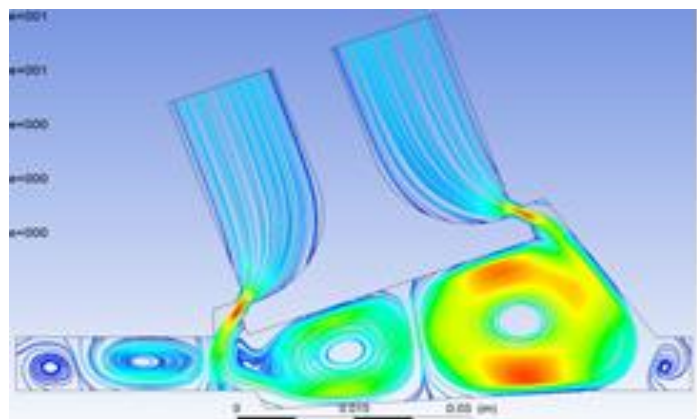

Figure 12. Suction stroke $30^{\circ} \mathrm{CA}$

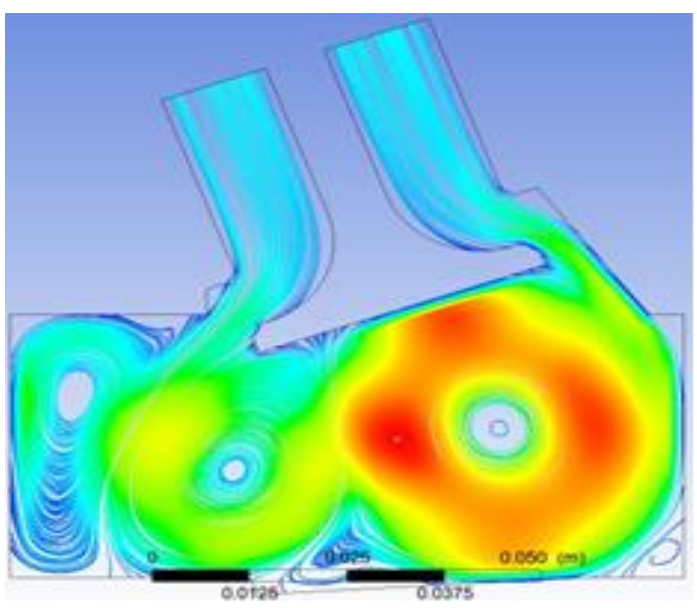

Figure 14 Suction stroke $90^{\circ} \mathrm{CA}$ 
The images obtained at 3000 RPM show that the highest flow rate was about $35 \mathrm{~m} / \mathrm{s}$ (Figures 11, 12, 13 and 14). As the engine revolution increases, the velocity of the air entering the cylinder also increases. However, the vortices formed at 3000 RPM are similar to those formed at 900 RPM

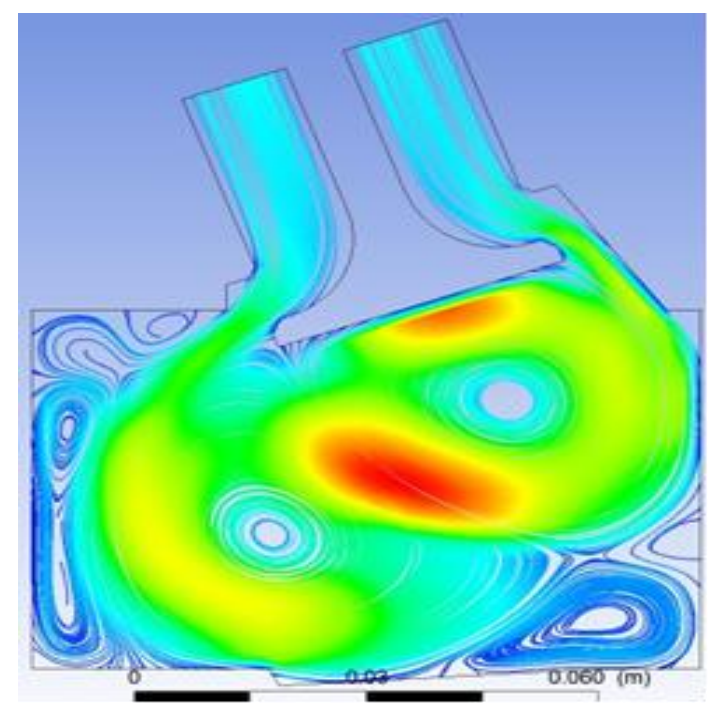

Figure 15 Suction stroke $120^{\circ} \mathrm{CA}$

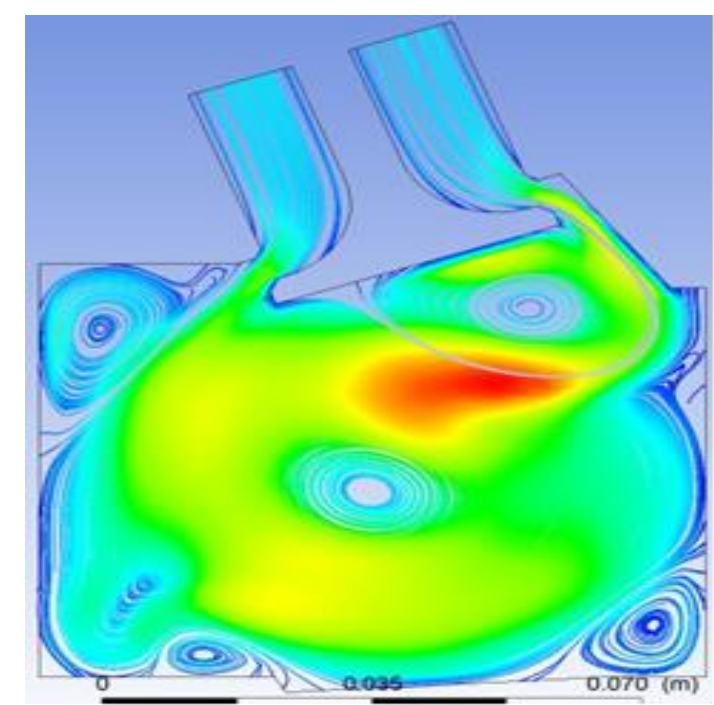

Figure 16 Suction stroke $150^{\circ} \mathrm{CA}$

Figure 15-16 shows that there is a main vortex in the center formed at 3000 RPM and four small vortices in the corners. The comparison of $150^{\circ} \mathrm{CA}$ and $900 \mathrm{RPM}$ shows that there is an increase in the number of small vortices. Figure 17-18 shows that rich mixture was observed in the middle part and lean mixture at the corners.

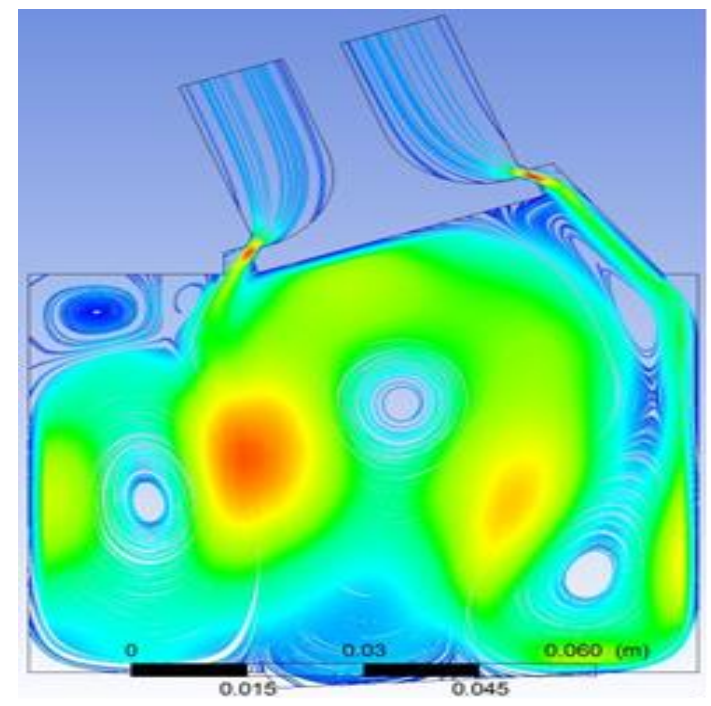

Figure 17 Suction stroke $180^{\circ} \mathrm{CA}$

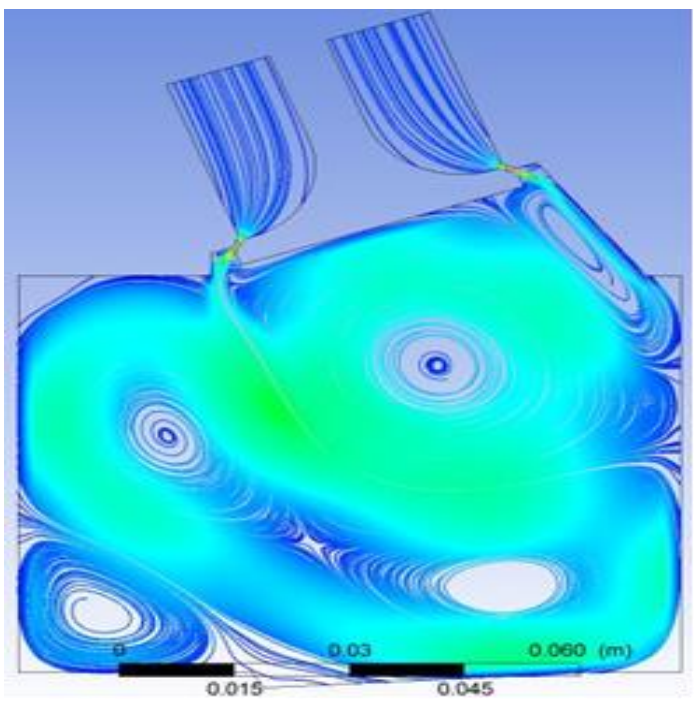

Figure 18 Suction stroke $200^{\circ} \mathrm{CA}$

At $180^{\circ} \mathrm{CA}$ and $200^{\circ} \mathrm{CA}$, the small vortices grew to a large size and the mixture was unstable at points far from the spark plug. 


\subsection{Air Motions at 5000 RPM suction stroke}

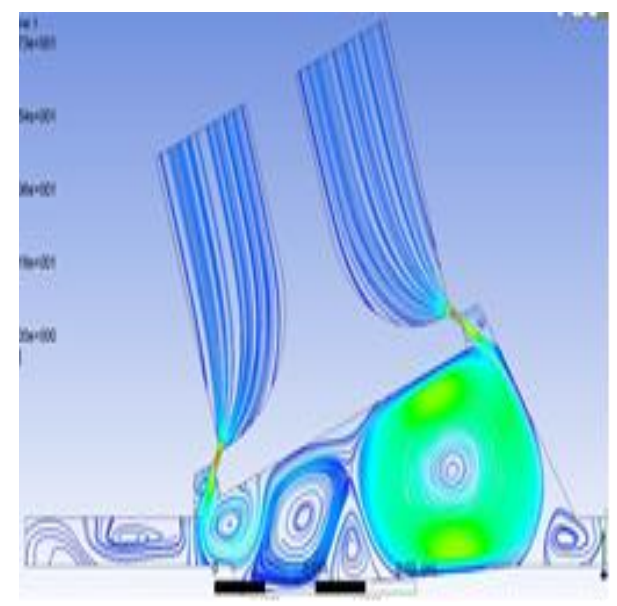

Figure 19 Beginning of suction stroke $-20^{\circ} \mathrm{CA}$

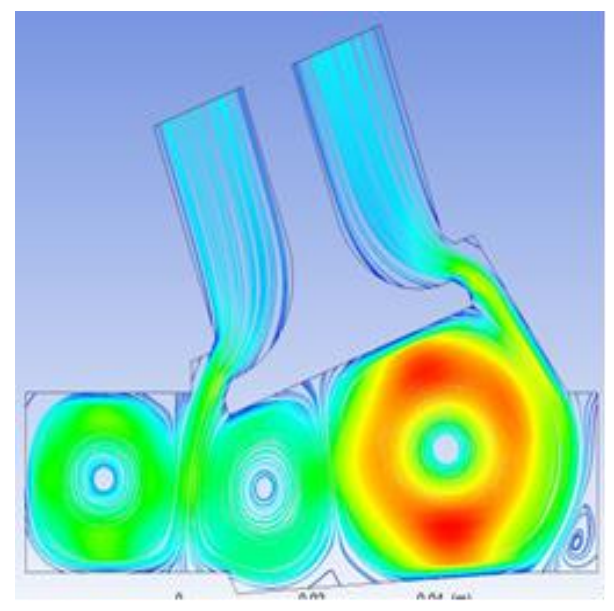

Figure 21 Suction stroke $60^{\circ} \mathrm{CA}$

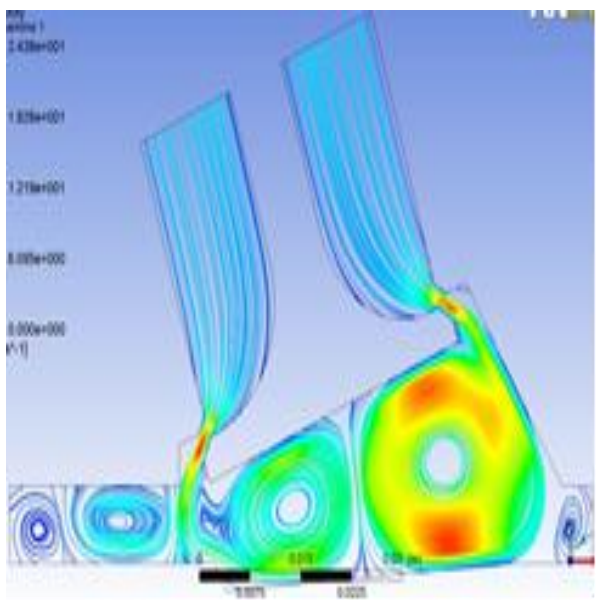

Figure 20 Suction stroke $30^{\circ} \mathrm{CA}$

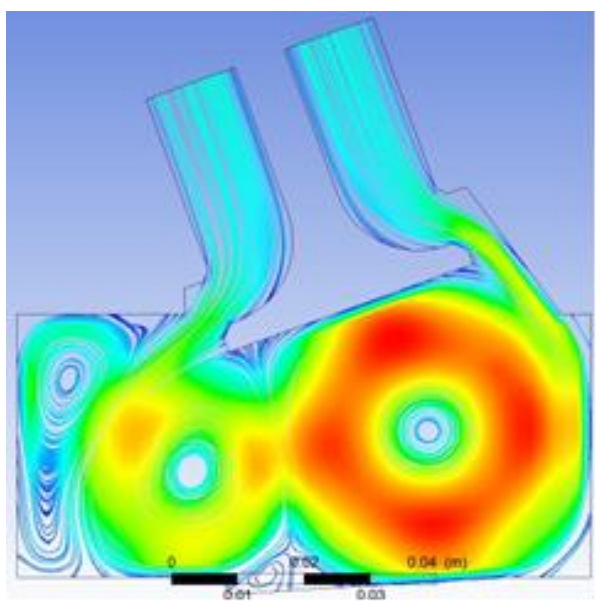

Figure 22 Suction stroke $90^{\circ} \mathrm{CA}$

In Figures 19 to 22 at 5.000 RPM, the speed at the valve section was up to $55 \mathrm{~m} / \mathrm{s}$ and the resulting vortices consisted of two main vortices and small vortices.

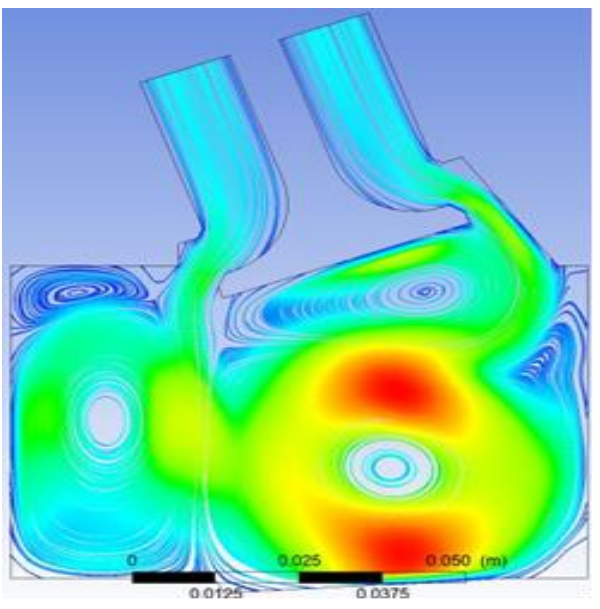

Figure 23 Suction stroke $120^{\circ} \mathrm{CA}$

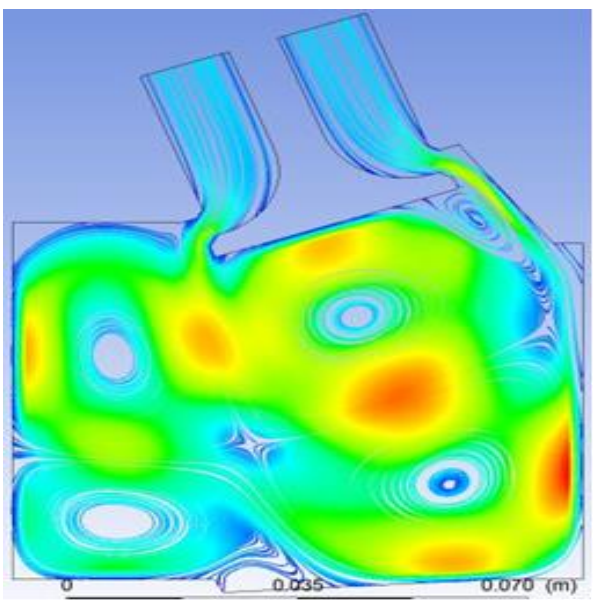

Figure 24Suction stroke $150^{\circ} \mathrm{CA}$ 


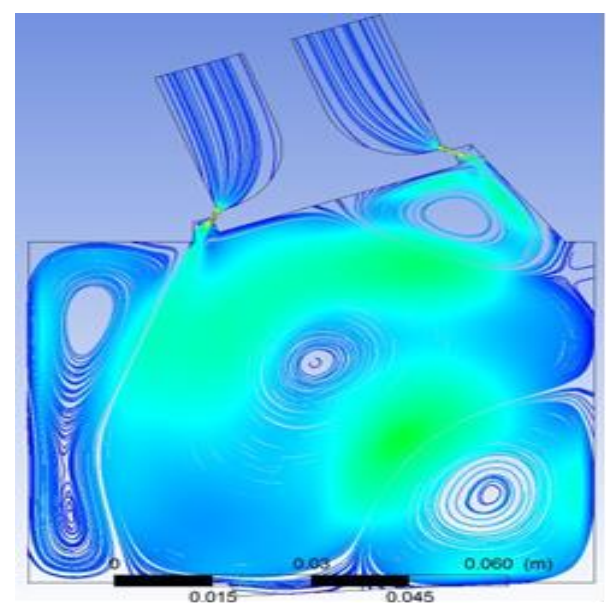

Figure 25 Suction stroke $200^{\circ} \mathrm{CA}$

In Figures 23 to 25 with the expansion of the cylinder volume, the mixture is concentrated in the middle of the cylinder at the end of the suction stroke. Small vortices are formed in front of the spark plug and at the corners.

\section{Conclusion}

Within the scope of power and efficiency enhancement efforts in internal combustion engines, combustion chamber design and the characteristics of air fuel mixture in the combustion chamber are of great importance. In this context, numerical analysis and modeling using computerized software before conducting experimental studies have many advantages such as time and cost effectiveness. The ANSYS Fluent software package is one of these computerized models. Numerous data such as flow events, thermal events, etc. can be obtained in models generated by the ANSYS Fluent software. Using the ANSYS Fluent software, this study carried out a twodimensional investigation of the combustion chamber and in-cylinder flow of the internal combustion engine and obtained the following results.

From a three-dimensional perspective, the turbulence generated has a mushroom shape. The upward motion of the piston causes the resulting vortices to merge with one another. The flow of the engine at 900 RPM is more uniform and as the engine speed increases, the vortices become more distorted and create different mixing zones. The diffusivity of the vortices and different mixing zones make combustion difficult. It is known that combustion may cause knocking in a nonhomogeneous mixture and that exhaust emissions are negatively affected by incomplete combustion. Complete combustion depends on proper formation of a flame front after the ignition of the spark and spread of the flame all over the combustion chamber by first gaining a laminar structure and then turbulence as the flame speed and feed rate increase. A flame front that does not start properly may disintegrate and combustion may be terminated before completion depending on the combustion chamber and mixing conditions. These, of course, depend on the geometry of the combustion chamber, performance of the heat transfer and cooling system, increased gas quantity, and structure, shape and temperature of the mixture. The flame structure and speed depend directly on the preparation of the mixture and on the mixing ratio. It is necessary to optimize these parameters to maximize these values for each engine type. Adhering to the experimental methods in the optimization of these values makes it difficult to obtain the results. The stated conditions are, of course, of vital importance for the simulation studies carried out.

The data indicate that avoiding sharp corners will be beneficial for an ideal in-cylinder flow and that positioning the suction valves close to the vertical axis of the cylinder will contribute to mixture production, combustion and volumetric efficiency.

It is suggested that the ANSYS Fluent software and dynamic mesh for a three-dimensional investigation of in-cylinder flow.

\section{Conflicts of interest}

The authors have stated that they have no conflicts of interest. 


\section{References}

[1] Can I., LPG ile çalışan benzinli bir motora kademeli dolgu yapılmasının performans üzerindeki etkisinin deneysel olarak incelenmesi, Firat Üniversitesi Fen Bilimleri Enstitüsü, (Doktora Tezi) Elazı $\breve{g}$, (2009) 138.

[2] Akar R., Combustion chamber design with computational fluid dynamic, University of cukurova. science institute, (Msc Thesis) Adana (2005),

[3] Müjdat F., Yeni nesil yanma odalarında akış ve 1s1 transferlerinin sayısal olarak modellenmesi Firat Üniversitesi Fen Bilimleri Enstitüsü, (Yüksek Lisans Tezi) Elazı $\breve{g}$, (2010) 62.

[4] Michael C., Drake T. D., Fansler A., Lippert M., Stratified-charge combustion modeling and imaging of a spray-guided direct-injection sparkignition engine, Proceedings of the Combustion Institute, 30 (2005) 2683- 691

[5] $\mathrm{Wu} \mathrm{H}$. W., Perng S. W., LES analysis of turbulent flow and heat transfer in motored engines with various SGS models, Int. Heat Mas. Transfer, 45 (2002) 2315- 2328.

[6] Altin İ., Bilgin A., A parametric study on the performance parameter of a twin-spark SI engine, Energy Conv. Manag., 50 (2009) 1902-1907.

[7] Coşkun G., Toksöz S., Soyhan H. S., Halıcı F., Combustion analysis of an HCCI engine using computational fluid dynamics, 6th International Advanced Technologies Symposium (IATS'11), Turkey, (2011) 16-18.

[8] T.C. millî eğitim bakanliği motorlu araçlar teknolojisi egzoz emisyon kontrolü 525 mt 0300 Ankara. Available at: http://megep.meb.gov.tr/mte_program_modul/m oduller_pdf/Egzoz\%20Emisyon\%20Kontrol\%C3 \%BC.pdf. Retrieved 2011.
[9] Heywood J.B., Internal combustion engines fundamentals, Mc Graw Hill, A.B.D., (1988) 316320.

[10] Zhao H., HCCI and CAI Engines for the Automotive Industry, Woodhead Publishing Limited, England, (2007) 19-39.

[11] Yap D., Karlovsky J., Megaritis A., Wyszynski L., $\mathrm{Xu} \mathrm{H.,} \mathrm{An} \mathrm{investigation} \mathrm{into} \mathrm{propane}$ homogeneous charge compression ignition (HCCI) engine operation with residual gas trapping, Fuel, 84 (18) (2005) 2372- 2379.

[12] Can Ç., Ahmet U., Hamit S., The Investigation of The Effects of RON 45 Fuel on Combustion and Engine Performance in a HCCI Gasoline Engine, 7 th International Advanced Technologies Symposium (IATS'13), Turkey, (2013) 1-6.

[13] Rafig M., Demir B., Hikmet A., Temel G., Düşük emisyonlu ve yüksek verimli yeni bir kademeli dolgulu benzin motoru, Mühendis ve Makine, 46 (549) (2005) 42-50.

[14] Ricardo H.R., Recent work on internal combustion engine, SAE. Journal, (1922) 305306.

[15] Mehdiyev, R.I., Wolanski, P., Bi-modal combustion chamber for a stratified charge engine, SAE. Journal, 01 (0196) (2000) 53-57. 